\title{
CORRECTION
}

View Article Online

View Journal I View Issue

\section{Correction: Ionic thermoelectric paper}

Cite this: J. Mater. Chem. A, 2017, 5 ,
20053

Fei Jiao, ${ }^{a}$ Ali Naderi, ${ }^{\mathrm{b}}$ Dan Zhao, ${ }^{\text {a }}$ Joshua Schlueter, ${ }^{\mathrm{C}}$ Maryam Shahi, ${ }^{\mathrm{c}}$

Jonas Sundström, ${ }^{b}$ Hjalmar Granberg, ${ }^{b}$ Jesper Edberg, ${ }^{a}$ Ujwala Ail, ${ }^{a}$ Joseph Brill, ${ }^{c}$

Tom Lindström, ${ }^{b}$ Magnus Berggren ${ }^{\mathrm{a}}$ and Xavier Crispin*a

DOI: $10.1039 / \mathrm{c} 7 \operatorname{ta9} 0197 f$

www.rsc.org/MaterialsA

Correction for 'Ionic thermoelectric paper' by Fei Jiao et al., J. Mater. Chem. A, 2017, 5, 16883-16888.

The authors regret that the incorrect affiliation was used for one of the authors, Ali Naderi, on the original manuscript. The corrected list of authors and affiliations for this paper is shown above.

The Royal Society of Chemistry apologises for these errors and any consequent inconvenience to authors and readers. 